\title{
Congenital pyloric mucosal fold resulting in an antral valve outflow obstruction in a bull terrier
}

\author{
P. Pazzi, M. J. Hartman and J. P. Schoeman \\ Department of Companion Animal Clinical Studies, Faculty of Veterinary Science, University of Pretoria, \\ Onderstepoort 0110, South Africa
}

An under-sized 3 month old female bull terrier was referred with a history of regurgitation since 3 days of age. Thoracic radiographs were unremarkable, while abdominal radiographs showed a distended stomach, despite a 12 hour fast. Abdominal ultrasonography revealed gastric outflow obstruction of unclear aetiology. Coeliotomy was performed, during which an excessive mucosal fold at the pyloric antrum was excised. Histopathology of the pyloric fold revealed mild oedema and fibrosis of the mucosal tissue. The dog made a complete recovery, with resolution of regurgitation and grew to within the expected breed size. In the authors' opinion, this is the first canine report of congenital antral mucosal valve resulting in gastric outflow obstruction, and only the second report in any species.

Key words: Congenital, gastric, obstruction, dog

\section{INTRODUCTION}

Gastric outlet obstruction is characterized by delayed gastric emptying that results in retention and vomiting of food unrelated to feeding. In healthy dogs, the stomach starts to empty within 30 minutes of feeding and is completely empty within 3-6 hours (Herdt 2007). Delayed gastric emptying occurs when food is retained in the stomach for longer than 6-12 hours after a meal. Normal stomach emptying time is influenced by volume, caloric density and fibre content of the meal (Herdt 2007). Vomiting is the predominant sign associated with delayed gastric emptying; other signs include abdominal discomfort, distension, bloating and intermittent anorexia (Washabau 2003, Simpson 2010).

The pyloric part of the stomach comprises the pyloric antrum which begins at the angular notch, the short and narrowed pyloric canal and the pylorus which surrounds the opening into the 
duodenum and the pyloric sphincter (Evans 1993). Pyloric outflow obstruction is an uncommon finding in dogs and may result from a physical obstruction or defective propulsive activity. Physical pyloric outflow obstruction can be divided into congenital and acquired causes (Washabau 2003). Causes of congenital pyloric outflow obstructions in dogs are limited to smooth muscle hypertrophy resulting in pyloric stenosis, and gastric polyps (Happe and others 1977, Pearson 1979, Abel and others 2002, Diana and others 2009, Kuan and others 2009). Acquired pyloric outflow obstruction in a 10 week old puppy has also been documented secondary to severe pyloric calcification as a result of acute renal failure from leptospirosis (Michel and others 2011).

In the only case report of congenital outflow obstruction in cats, both the queen and two of her offspring were diagnosed with pyloric stenosis (Twaddle 1971). The kittens first exhibited signs at fourteen weeks of age, raising the question of acquired stenosis because congenital signs of gastric outlet obstruction are usually already evident from 2-12 weeks of age in humans (Twaddle 1971, Ranells and others 2011).

The same causes of congenital pyloric outflow obstruction as reported in dogs are reported in humans, but rare additional causes include pyloric membrane/web, pyloric atresia, or antral membrane/web/diaphragm (Mitchell and others 1979, Nissan and others 1997, Lui and others 2000, Okoye and others 2000). An antral mucosal valve causing gastric outlet obstruction has previously been reported in one neonate (Pratap and others 2006).

In the authors' opinion, this is the first report in animals of a congenital excessive pyloric mucosal fold acting as an antral valve, causing delayed gastric outflow obstruction and only the second in any other species. 


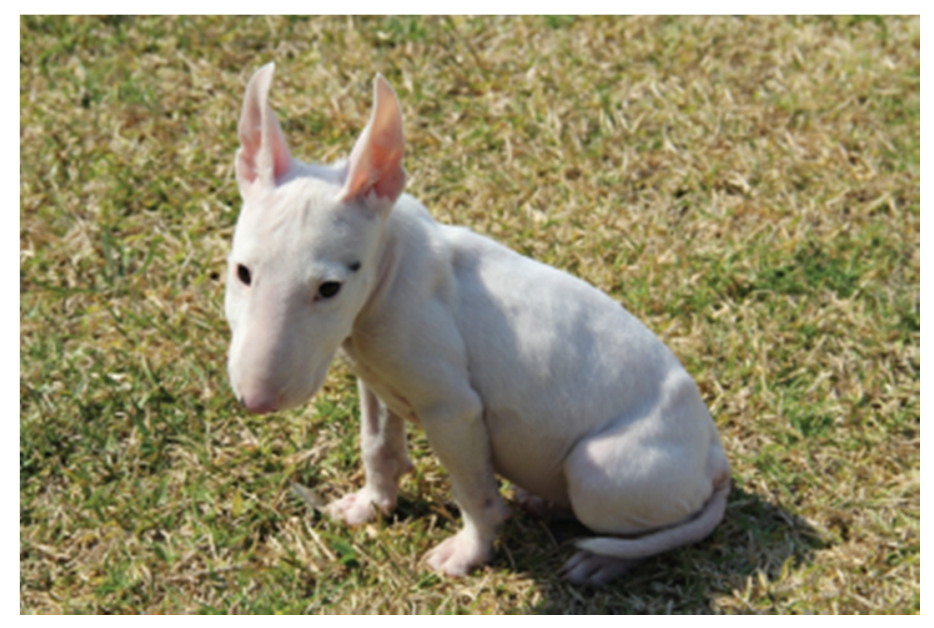

Fig. 1. The undersized Bull Terrier patient at presentation.

A 3 month old female bull terrier presented with a history of non-bilious regurgitation that occurred approximately10 minutes to one hour after feeding. It had started three days after birth and persisted regardless of behavioural (height feeding) and dietary alterations. Clinical examination revealed a puppy with a body condition score of $2 / 5$ and approximately $1 / 5$ of the expected size for the breed and age (Fig 1). The patient was mildly depressed and hypothermic $\left(36.8^{\circ} \mathrm{C}\right.$, reference range $\left.38-38.5^{\circ} \mathrm{C}\right)$, while the rest of the clinical examination was unremarkable. Haematology revealed moderate thrombocytosis $\left(743\right.$, reference interval 200 to $\left.500 \times 10^{9} / \mathrm{L}\right)$. A biochemistry panel, including chloride and total thyroxine, was within reference intervals, except for mild hypoproteinaemia (47.3, reference interval 53 to $75 \mathrm{~g} / \mathrm{L}$ ), mild hypoglobulinaemia (16.5, reference interval 20 to $37 \mathrm{~g} / \mathrm{L})$ and decreased creatinine (26, reference interval 40 to $133 \mathrm{umol} / \mathrm{L}$ ). An intravenous $5 \%$ dextrose-ringers lactate infusion was started at maintenance rates. The patient was starved for 12 hours and thoracic radiographs revealed only a mild bronchial pattern with no indication of megaoesophagus, while abdominal radiographs showed a distended stomach displacing the descending colon to the right. Abdominal ultrasound revealed a grossly distended stomach with speckled hypoechoic fluid and food particles. In the pyloric region there was no obvious transit of food or liquid passing through to the duodenum, despite mild gastric contractions. The gastric mucosa appeared irregularly thickened near 
the pylorus, with a prominent submucosa. A pyloric outflow obstruction was suspected, although the exact cause of obstruction could not be determined, and an exploratory coeliotomy was performed.

A ventral midline coeliotomy was performed under general anaesthesia using premedication with $0.1 \mathrm{mg} / \mathrm{kg}$ diazepam iv (Valium, Lennon Medicine), induction with $4 \mathrm{mg} / \mathrm{kg}$ propofol iv (Propofol $1 \%$, Fresenius Kabi), and maintained on isoflurane (Isofor, Safeline Pharmaceuticals) and oxygen inhalation anaesthetics. Inspection of the stomach revealed a palpably thickened structure associated with the lumen of the pyloric antrum. A full thickness longitudinal incision was made in the ventral

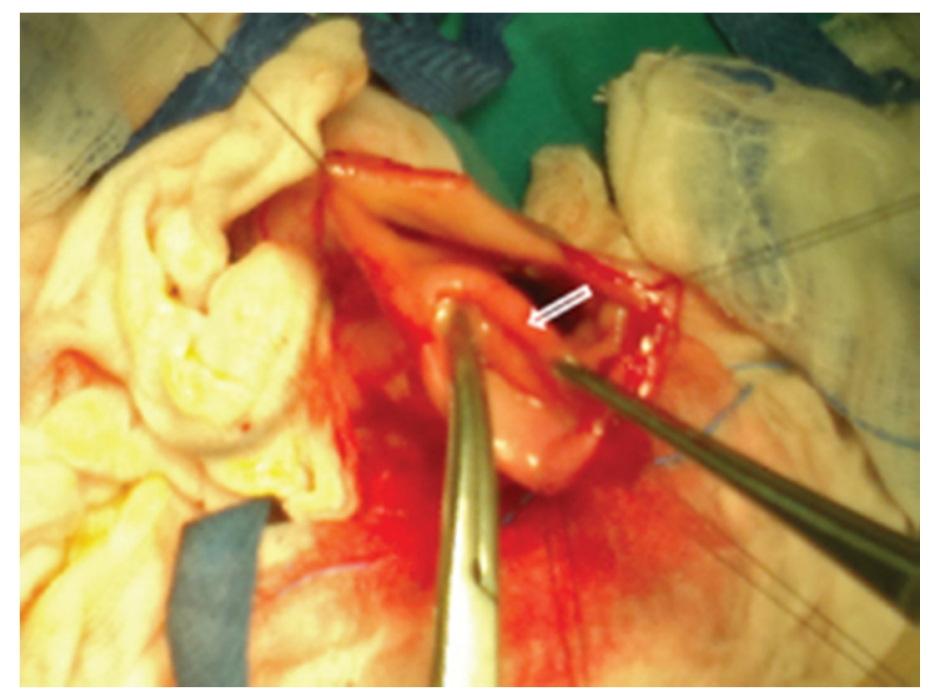

Fig. 2. The excessive mucosal fold is pointed out by the straight DeBakey forceps and the arrow. The curved Spencer Wells artery forceps is introduced into the pylorus.

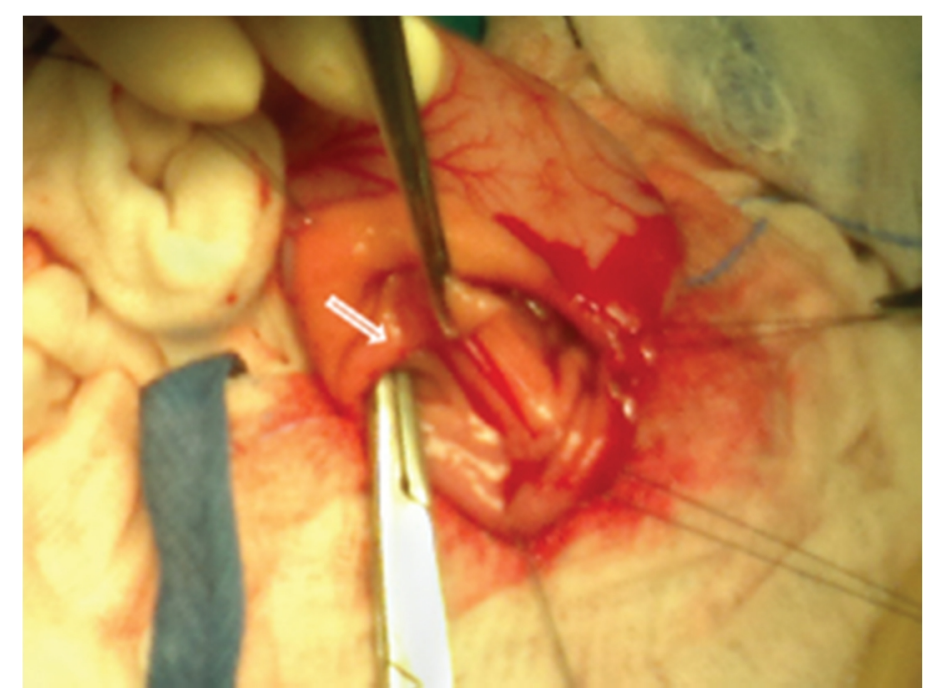

Fig. 3. The excessive mucosal fold (arrow) is manipulated by the straight DeBakey forceps. The curved Spencer Wells artery forceps is introduced into the pylorus. 
surface of the pyloric antrum. Subsequently an excessive mucosal fold was discovered in the area of transition between the pyloric antrum and pyloric canal about $1.5 \mathrm{~cm}$ oral to the pylorus. It involved approximately two thirds of the antral circumference caudally and the mucosal fold was physically able to occlude the pylorus resulting in subsequent obstruction. (Fig 2 and 3). The mucosal fold was resected and the mucosa was sutured with 1.5 metric polyglecaprone 25 (Monocryl, Ethicon) using a simple continuous suture pattern (Fig 4). The wall of the pyloric antrum was closed with 1.5 metric polydioxanone (PDS, Ethicon) using a simple continuous suture pattern in both the mucosa-

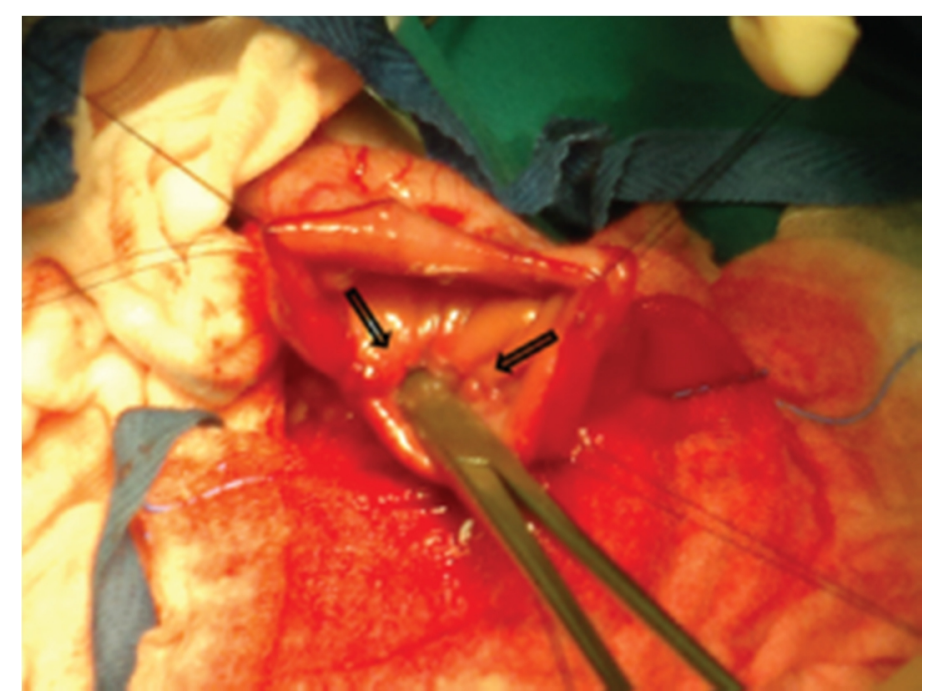

Fig. 4. After resection of the excessive mucosal fold the entrance to the pylorus is clearly depicted by the Spencer Wells artery forceps entering the pylorus (arrows).

submucosal (knots placed intraluminal) and seromuscular layers (knots placed extramural) of the terminal narrower part of the pyloric antrum, followed by a Connell suture pattern in the mucosasubmucosal layer and a Lembert suture pattern in the seromuscular layer as the luminal diameter of the pyloric antrum increased. No evidence of obstruction or other pathology was found during inspection of the remainder of the gastrointestinal tract or abdomen. The abdominal wall was closed routinely. Post-surgically the patient was maintained on intravenous fluids and additional treatment included 20mg/kg amoxicillin-clavulanic acid (Augmentin, GlaxoSmithKline) iv, twice a day; fentanyl (Fentanyl, Boden/Intramed) at 3mcg/kg/h for 24 hours, metoclopramide (Clopamon, Aspen) at $1 \mathrm{mg} / \mathrm{kg} / 24$ hours constant rate infusion for 5 days; omeprazole (Omez, Dr. Reddy's) at $0.7 \mathrm{mg} / \mathrm{kg}$ 
orally once a day for 10 days and sucralfate (Ulsanic, Pharmacare) at 250mg orally twice a day for 10 days. Twelve hours after surgery, feeding was initiated at 4 hourly intervals. Regurgitation initially occurred twice but then stopped for the duration of the 6 day hospital stay.

Histopathology of the excised pyloric fold revealed no hypertrophic or inflammatory changes with only mild oedema and fibrosis of the mucosa layer and normal submucosal tissue. The patient was discharged with amoxicillin/clavunate (Synulox, Pfizer) $25 \mathrm{mg} / \mathrm{kg}$ twice a day orally for 14 days. Two weeks after discharge the patient had only regurgitated once. Thirty weeks post-surgery the owners reported that the patient was healthy, with no regurgitation and of expected size for the breed (Fig 5).

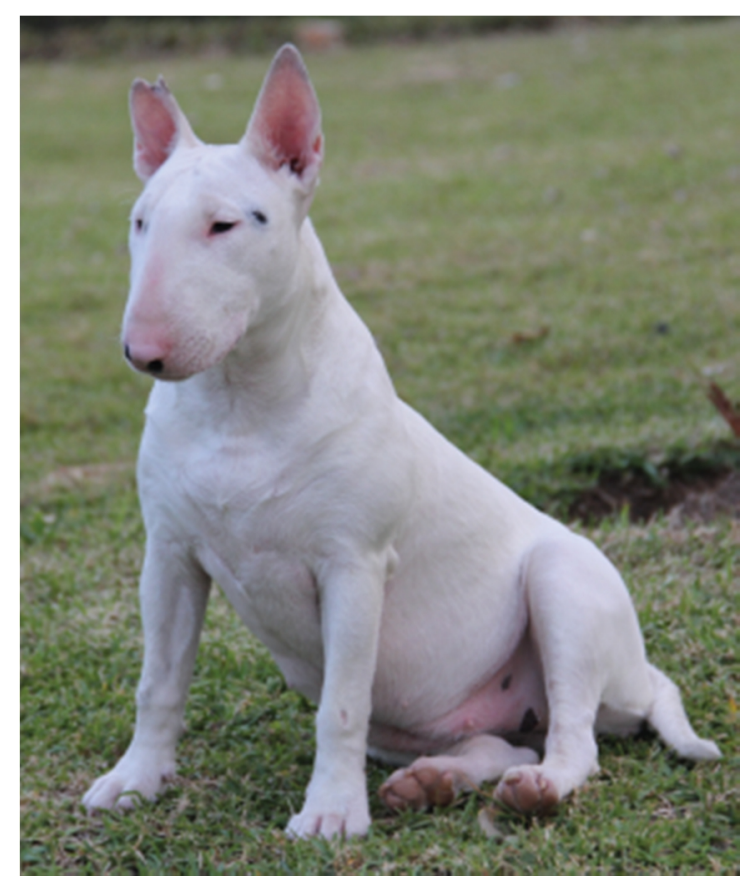

Fig. 5. The Bull Terrier patient twenty weeks after corrective surgery.

\section{DISCUSSION}

The typical presentation in humans and dogs with congenital gastric outflow obstruction is nonbilious vomiting within the first two to twelve weeks of life (Kuan and others 2009, Ranells and others 2011). In this case, non-bilious regurgitation started at 3 days of age and was more prominent 
than vomiting and was most likely due to volume overload of the stomach that lead to retrograde reflux.

The diagnosis of gastric outflow obstruction was based on clinical signs, supportive ultrasound findings and the excessive mucosal fold found during surgery. The absence of smooth muscle hypertrophy in the histopathology samples and lack of circumferential thickening of the pylorus excluded the possibility of pyloric hypertrophic stenosis (Abel and others 2002, Ranells and others 2011). In humans an antral web is characterised as a thin septum, located 1- to 7-cm from the pylorus and typically projects into the gastric lumen perpendicular to the long axis of the antrum (Bell and others 1977, Tiao and others 2005). The possibility of antral web was excluded both during surgery and histopathologically. The clinical examination, surgical findings, histopathology and response to surgery were most consistent with the reported findings in a new born child with an antral mucosal valve (Pratap and others 2006). In the infant report the valve effect was clearly visualised after saline loading, which was not performed in this canine case, but resection of the excessive mucosal fold successfully relieved the pyloric outflow obstruction in both cases.

Surgery is the mainstay of correction in most causes of physical pyloric outflow obstruction. The treatment of choice in humans and dogs for hypertrophic pyloric stenosis is a Fredet-Ramstedt pyloromyotomy, although conservative medical treatment with atropine sulphate also may be successful in milder cases (Matthiesen and Walter 1986, Yamataka and others 2000, Kawahara and others 2005, Sola and Neville 2009). Two kittens with pyloric stenosis were also treated with pyloroplasty (Twaddle 1971). In humans most antral webs can be managed with a simple incision to excise the web, endoscopic transection or laser lysis of the web (Al-Kawas 1988). Unlike other causes of gastric outlet obstruction, the prognosis after antral mucosal valve excision should be excellent, because pyloroplasty, which may adversely affect the antropyloric pump mechanism, is not required (Pratap and others 2006).

The aetiology of the various causes of congenital outflow obstruction is under investigation. A specific gene responsible for human congenital pyloric hypertrophic stenosis has not yet been 
discovered, although several susceptible loci have been identified (Panteli 2009). The aetiology of the antral web is still controversial. It may originate from incomplete canalization of the foregut during the 5-6th week of embryonal development, as an incomplete form of membranous atresia (Bell and others 1977, Bell and others 1978, Lui and others 2000). However, an acquired antral web in adults due to peptic diseases has also been documented (Huggins and others 1982). Due to the scarcity of reported cases of an antral mucosal valve causing gastric outflow obstruction in both humans and animals, the aetiology of the valve is unclear and can only be speculated, although the antral valve might share a common embryological origin with the antral web and other lesions causing congenital gastric outlet obstruction in humans (Bell and others 1978).

In conclusion, in the authors' opinion, this is the first reported case of canine congenital excessive pyloric mucosal fold acting as an antral one-way valve. The response to surgery; resultant compensatory growth and lack of recurrence of clinical signs support the diagnosis, with a good prognosis subsequent to corrective surgery. This should be considered as a differential in any dog with congenital regurgitation or vomiting.

\section{References}

Abel, R. M., Doré, C. J., Bishop, A. E., Facer, P., Polak, J. M. \& Spitz, L. (2002) A quantitative study of the neural changes underlying pyloric stenosis in dogs. Anatomia Histologia Embryologia 31, 139143

Al-Kawas, F. H. (1988) Endoscopic laser treatment of an obstructing antral web. Gastrointestinal Endoscopy 34, 349-351

Bell, M. J., Ternberg, J. L., Keating, J. P., Moedjona, S., McAlister, W. \& Shackelford, G. D. (1978) Prepyloric gastric antral web: a puzzling epidemic. Journal of Pediatric Surgery 13, 307-313

Bell, M. J., Ternberg, J. L., McAlister, W., Keating, J. P. \& Tedesco, F. J. (1977) Antral diaphragm--a cause of gastric outlet obstruction in infants and children. Journal of Pediatrics 90, 196-202

Diana, A., Penninck, D. G. \& Keating, J. H. (2009) Ultrasonographic appearance of canine gastric polyps. Veterinary Radiology \& Ultrasound 50, 201-204 
Evans, H. E., (1993) The Digestive Apparatus and Abdomen. In: Miller, M. E., Evans, H. E. (1993) Miller's anatomy of the dog. Saunders, Philadelphia. pp 385-462

Happe, R. P., Gaag, I. V., Wolvekamp, W. T. C. \& Toorenburg, J. V. (1977) Multiple polyps of the gastric mucosa in two dogs. Journal of Small Animal Practice 18, 179-189

Herdt, T. H., (2007) Gastrointestinal physiology and metabolism. In: Cunningham, J. G., Klein, B. G. Textbook of Veterinary Physiology. Saunders, an imprint of Elsevier Inc, St. Louis, MO. pp 299-407

Huggins, M. J., Friedman, A. C., Lichtenstein, J. E. \& Bova, J. G. (1982) Adult acquired antral web. Digestive Diseases \& Sciences 27, 80-83

Kawahara, H., Takama, Y., Yoshida, H., Nakai, H., Okuyama, H., Kubota, A., Yoshimura, N., Ida, S. \& Okada, A. (2005) Medical treatment of infantile hypertrophic pyloric stenosis: should we always slice the "olive"?. Journal of Pediatric Surgery 40, 1848-1851

Kuan, S., Hoffmann, K. \& Tisdall, P. (2009) Ultrasonographic and surgical findings of a gastric hyperplastic polyp resulting in pyloric obstruction in an 11-week-old French Bulldog. Australian Veterinary Journal 87, 253-255

Lui, K. W., Wong, H. F., Wan, Y. L., Hung, C. F., Ng, K. K. \& Tseng, J. H. (2000) Antral web--a rare cause of vomiting in children. Pediatric Surgery International 16, 424-425

Matthiesen, D. T., Walter, M. C. (1986) Surgical treatment of chronic hypertrophic pyloric gastropathy in 45 dogs. Journal of the American Animal Hospital Association 22, 241-247

Michel, E., Kook, P. H., Voss, K., Boretti, F. \& Reichler, I. M. (2011) Generalized metastatic intestinal and cutaneous calcinosis in a Hovawart-puppy with leptospirosis. SAT, Schweizer Archiv fur Tierheilkunde 153, 27-31

Mitchell, K. G., McGowan, A., Smith, D. C. \& Gillespie, G. (1979) Pyloric diaphragm, antral web, congenital antral membrane--a surgery rarity?. British Journal of Surgery 66, 572-574

Nissan, A., Seror, D. \& Udassin, R. (1997) Gastric outlet obstruction caused by prepyloric mucosal diaphragm mimicking duodenal ulcer: a case report. Acta Paediatrica 86, 116-118

Okoye, B. O., Parikh, D. H., Buick, R. G. \& Lander, A. D. (2000) Pyloric atresia: five new cases, a new association, and a review of the literature with guidelines. Journal of Pediatric Surgery 35, 12421245

Panteli, C. (2009) New insights into the pathogenesis of infantile pyloric stenosis. Pediatric Surgery International 25, 1043-1052

Pearson, H. (1979) Pyloric stenosis in the dog. Veterinary Record 105, 393-394

Pratap, A., Tiwari, A., Agrawal, C. S., Shreshta, P., Anchal, N. \& Shakya, V. C. (2006) Antral mucosal valve: a rare cause of gastric outlet obstruction in newborn. Journal of Pediatric Surgery 41, 856-858 
Ranells, J. D., Carver, J. D. \& Kirby, R. S. (2011) Infantile hypertrophic pyloric stenosis: epidemiology, genetics, and clinical update. Advances in Pediatrics 58, 195-206

Simpson, K. W., (2010) Diseases of the stomach. In: Ettinger, S. J., Feldman, E. C. Textbook of Veterinary Internal Medicine. Elsevier Saunders, St. Louis, Mo. pp 1504-1526

Sola, J. E., Neville, H. L. (2009) Laparoscopic vs open pyloromyotomy: a systematic review and meta-analysis. Journal of Pediatric Surgery 44, 1631-1637

Tiao, M. M., Ko, S. F., Hsieh, C. S., Ng, S. H., Liang, C. D., Sheen-Chen, S. M., Chuang, J. H. \& Huang, H. Y. (2005) Antral web associated with distal antral hypertrophy and prepyloric stenosis mimicking hypertrophic pyloric stenosis. World Journal of Gastroenterology 11, 609-611

Twaddle, A. A. (1971) Congenital pyloric stenosis in two kittens corrected by pyloroplasty. New Zealand Veterinary Journal 19, 26-27

Washabau, R. J. (2003) Gastrointestinal motility disorders and gastrointestinal prokinetic therapy. Veterinary Clinics of North America - Small Animal Practice 33, 1007-1028

Yamataka, A., Tsukada, K., Yokoyama-Laws, Y., Murata, M., Lane, G. J., Osawa, M., Fujimoto, T. \& Miyano, T. (2000) Pyloromyotomy versus atropine sulfate for infantile hypertrophic pyloric stenosis. Journal of Pediatric Surgery 35, 338-341 